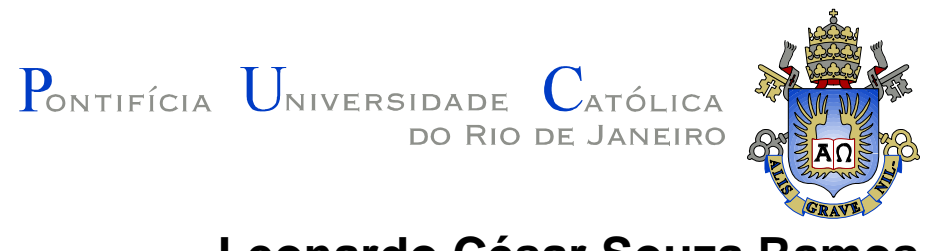

Leonardo César Souza Ramos

A Sociedade Civil em Tempos de Globalização: Uma Perspectiva Neogramsciana

\begin{abstract}
Dissertação de Mestrado
Dissertação apresentada como requisito parcial para obtenção do título de Mestre pelo Programa de PósGraduação em Relações Internacionais da PUC-Rio.
\end{abstract}

Orientador: José María Gómez 


\title{
A Sociedade Civil em Tempos de Globalização: Uma Perspectiva Neogramsciana
}

\begin{abstract}
Dissertação apresentada como requisito parcial para obtenção do título de Mestre pelo Programa de PósGraduação em Relações Internacionais da PUC-Rio. Aprovada pela Comissão Examinadora abaixo assinada.
\end{abstract}

José María Gómez

Orientador

Instituto de Relações Internacionais - PUC-Rio

João Franklin Abelardo Pontes Nogueira Instituto de Relações Internacionais - PUC-Rio

Carlos Nelson Coutinho Escola de Serviço Social - UFRJ

João Franklin Abelardo Pontes Nogueira Coordenador Setorial do Centro de Ciências Sociais - PUC-Rio 
Todos os direitos reservados. É proibida a reprodução total ou parcial do trabalho sem autorização da universidade, do autor e do orientador.

\section{Leonardo César Souza Ramos}

Graduou-se em Relações Internacionais pela PUC Minas (Pontifícia Universidade Católica de Minas Gerais) em 2002. Participou de congressos sobre Gramsci e Mercosul. É professor de Relações Internacionais do UNI-BH (Centro Universitário de Belo Horizonte).

Ficha Catalográfica

Ramos, Leonardo César Souza

A sociedade civil em tempos de globalização: uma perspectiva neogramsciana / Leonardo César Souza Ramos; orientador: José Maria Gómez. - Rio de Janeiro: PUC-Rio, Instituto de Relações Internacionais, 2005.

219 f. : il. ; $30 \mathrm{~cm}$.

Dissertação (mestrado) - Pontifícia Universidade Católica do Rio de Janeiro, Instituto de Relações Internacionais.

Inclui referências bibliográficas

1. Relações Internacionais - Teses. 2. Sociedade civil. 3. Hegemonia. 4. Contra-hegemonia. 5. Perspectivas neogramscianas. 6. Globalização. 7. Movimento altermundialista. I. Gómez, José María. II. Pontifícia Universidade Católica do Rio de Janeiro. Instituto de Relações Internacionais. III. Título. 


\section{Agradecimentos}

Ao Senhor Deus, por Sua sempiterna fidelidade, amor e presença;

À FAPERJ e à PUC-Rio, pelos auxílios concedidos, sem os quais este trabalho não poderia ter sido realizado;

Aos meus pais, pela educação, atenção e carinho - aspectos indispensáveis nos "momentos de crise";

À Jussara, mulher virtuosa de presença constante nos momentos de tristeza e alegria, angústia e contentamento;

Aos meus colegas da PUC-Rio, em especial o amigo Geraldo, sempre disposto a hospedar um mineiro viajante;

Ao meu orientador Professor José Maria Gómez, pelo estímulo para realização do trabalho e pelo exemplo de dedicação dado, fundamental não apenas para a feitura de uma dissertação mas também para a feitura de um acadêmico digno do nome;

Aos professores que participaram da Comissão examinadora;

A todos os professores e funcionários do IRI pelos ensinamentos, ajuda e disponibilidade;

A todos os professores que, de uma forma ou de outra foram fundamentais na feitura desse trabalho: Adam David Morton, Paulo Esteves, Onofre Santos Filho, Eugênio Diniz, Guy de Almeida, João Pontes Nogueira, Mark Rupert;

A todos os amigos e familiares que de uma forma ou de outra me estimularam ou me ajudaram neste processo árduo mas deveras recompensante. 


\section{Resumo}

Ramos, Leonardo César Souza. A sociedade civil em tempos de globalização: uma perspectiva neogramsciana. Rio de Janeiro: 2005. 219p. Dissertação de Mestrado - Instituto de Relações Internacionais, Pontifícia Universidade Católica do Rio de Janeiro.

A presente dissertação busca apresentar breves apontamentos para uma perspectiva neogramsciana da sociedade civil em tempos de globalização. Assim, após discorrer brevemente acerca das perspectivas neogramscianas da economia política global e dos conceitos de sociedade civil e globalização, serão explorados os impactos da globalização das relações sociais nos dois lados que se encontram em embate na sociedade civil. Serão apresentados também alguns dos dilemas enfrentados pela resistência progressista, como a questão da revolução passiva global e do aumento exponencial da coerção no âmbito mundial. Além disso, verse-á as transformações sofridas pelo "par conceitual” da sociedade civil - a sociedade política - e suas repercussões para os grupos sociais que atuam na sociedade civil. Por fim, será apresentada a importância e a necessidade de uma teoria crítica da economia política global para se pensar formas alternativas de globalização e o papel de Gramsci neste contexto. Ou seja, é exposta neste ponto a importância do legado gramsciano para se pensar não apenas a realidade social contemporânea mas também a sua transformação; daí a relevância de Gramsci também para os ativistas partícipes do movimento altermundialista - em outras palavras, são apresentadas as vantagens de se pensar a economia política global contemporânea a partir de uma perspectiva gramsciana.

\section{Palavras-chave}

Sociedade civil; hegemonia; contra-hegemonia; bloco histórico; perspectivas neogramscianas; globalização; movimento altermundialista. 


\section{Abstract}

Ramos, Leonardo César Souza. The civil society in times of globalization: a neogramscian perspective. Rio de Janeiro: 2005. 219p. MSc. Dissertation - Instituto de Relações Internacionais, Pontifícia Universidade Católica do Rio de Janeiro.

This dissertation aims to present some indications for a neogramscian perspective of the civil society in times of globalization. Therefore, after discuss briefly about the neogramscian perspectives of global political economy and the concepts of civil society and globalization, it will be explored the impacts of the globalization of the social relations in both sides that are in struggle in the civil society. It will be presented some of the dilemas facing by the progressive resistance, like the global passive revolution question and the exponential increase of the coertion in the global ambit. Also, it will be studied the transformations suffered by the "conceptual pair” of civil society - the political society - and their repercutions to the social groups that opetate in civil society. Finally, it will be presented the importance and the necessity of a global political economy critical theory in order to think alternative forms of globalization and the role of Gramsci in this context. In other words, in this point it is exposed the importance of gramscian legacy to think not only the contemporary social reality but also its transformation; this appoint to the reelvance of Gramsci also to the activist from the alterglobalist movement - in other words, there are presented the advantages of think the contemporary global political economy since a gramscian perspective.

\section{Keywords}

Civil society; hegemony; counter-hegemony; historic bloc; neogramscian perspectives; globalization; alterglobalist movement. 


\section{Sumário}

$\begin{array}{ll}1 . \text { Introdução } & 13\end{array}$

2. Gramsci: Uma Breve Introdução 22

2.1. Introdução $\quad 22$

2.2. A problemática da hegemonia 23

2.3. As concepções de Estado: "restrito" e "ampliado" 29

2.4. A questão da revolução-restauração ou da revolução passiva 31

2.5. Os intelectuais e a construção do bloco histórico 33

2.6. Conclusão 37

3 . A Reconstrução do Materialismo Histórico nos Estudos Internacionais: As Perspectivas Neogramscianas da Economia Política Global 39

3.1. Introdução 39

3.2. Hegemonia e Relações Internacionais: Três rotas para um encontro necessário

3.2.1. Robert W. Cox 42

3.2.2. Stephen R. Gill $\quad 51$

3.2.3. Mark E. Rupert 56

3.3. As perspectivas neogramscianas e os estudos internacionais (RI/EPI) $\quad 62$

3.4. O outro lado da moeda: As críticas aos neogramscianos 68

3.5. Conclusão: A pertinência das perspectivas neogramscianas 72

4. O conceito de sociedade civil $\quad 75$

$\begin{array}{ll}\text { 4.1. Introdução } & 75\end{array}$

4.2. Sociedade civil: Uma breve introdução histórica 76

4.3. O conceito de sociedade civil hoje: 4 matrizes teóricas de
destaque

4.3.1. Matriz neotocquevilliana 83

4.3.2. Matriz neoliberal $\quad 85$

4.3.3. Matriz habermasiana $\quad 88$

4.3.4. Matriz gramsciana 90

4.4. Conclusão: Prós e contras das matrizes teóricas contemporâneas 95

5. Globalização: Do que se trata afinal? 99

5.1. Introdução $\quad 99$

5.2. O que há de global na globalização? 100

5.3. As causas da globalização 108

5.4. A forma hodierna da globalização: A globalização neoliberal 112

5.5. Conclusão: A importância do estudo da globalização 119 
6. O conceito de sociedade civil face aos dilemas da globalização 121

6.1. Introdução 121

6.2. Novos transnacionalistas 123

6.3. Republicanismo Liberal 126

6.4. John Keane 130

6.5. "Marxismo político" 133

6.6. Conclusão: prós e contras da "sociedade civil global" 136

7 . Novos limiares da agência política coletiva no século XXI:

Apontamentos para uma perspectiva neogramsciana da sociedade civil em tempos de globalização 148

7.1. Introdução 148

7.2. As forças sociais dominantes e a globalização: A formação de uma fração transnacional da classe capitalista $\quad 150$

7.3. A globalização da resistência 160

7.3.1. O problema da revolução passiva e a dificuldade da contra-
hegemonia global

7.4. "O outro lado da força": A sociedade política em tempos de
globalização

7.5. Conclusão: Entre os dilemas e as possibilidades da construção de um bloco histórico altermundialista 186

8. Conclusão 192

9. Referências bibliográficas 200 
Lista de figuras

$\begin{array}{ll}\text { Figura } 1 & 43\end{array}$

$\begin{array}{ll}\text { Figura } 2 & 43\end{array}$

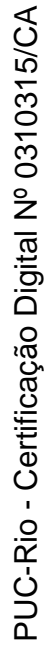




\section{Lista de tabelas}

$\begin{array}{lr}\text { Tabela I } & 158\end{array}$

$\begin{array}{lr}\text { Tabela II } & 159\end{array}$

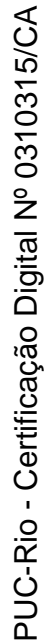




\section{Abreviaturas}

ALCA - Área de Livre Comércio das Américas

AMI - Acordo Multilateral de Investimentos

APEC - Cooperação Econômica Ásia-Pacífico

ASC (HSA) - Aliança Social Continental

ASEAN - Associação dos Países do Sudoeste Asiático

ATTAC - Associação pela Taxação das Transações Financeiras para o Auxílio dos Cidadãos

BIS - Banco Internacional de Compensações

CONAIE - Confederação das Nacionalidades Indígenas Equatorianas

CSCE - Conferência sobre Segurança e Cooperação Européia

EMU - União Econômica e Monetária Européia

EZLN - Exército Zapatista de Libertação Nacional

FEM - Fórum Econômico Mundial

FSA - Fórum Social Africano

FSE - Fórum Social Europeu

FSM - Fórum Social Mundial

FSMT - Fórum Social Mundial Temático

GATT - Acordo Geral de Tarifas e Comércio

ISO - Organização Internacional de Padronização

Mercosul - Mercado Comum do Sul

MST - Movimento dos Trabalhadores Sem Terra

NAFTA - Acordo de Livre-Comércio da América do Norte

OCDE - Organização para o Comércio e Desenvolvimento Econômico

OIT - Organização Internacional do Trabalho

OMC - Organização Mundial do Comércio

ONG - Organização Não Governamental

ONU - Organização das Nações Unidas

OTAN - Organização do Tratado do Atlântico Norte

PIB - Produto Interno Bruto

PNUD - Programa das Nações Unidas para o Desenvolvimento

UE - União Européia 


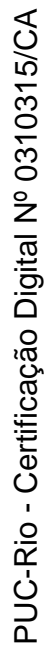

Não fosse o SENHOR, que esteve ao nosso lado, Israel que o diga.

Salmo 124:1 